\title{
Mayaro Virus: The Potential Role of Microbiota and Wolbachia
}

\author{
Thiago Nunes Pereira ${ }^{1}$, Fabiano Duarte Carvalho ${ }^{1}$, Jerônimo Nunes Rugani ${ }^{2}$, Vanessa Rafaela de Carvalho ${ }^{3,4} \mathbb{D}^{\text {, }}$ \\ Jaqueline Jarusevicius ${ }^{5}$, Jayme A. Souza-Neto ${ }^{3,4}$ (D) and Luciano Andrade Moreira ${ }^{1, *}$
}

1 Grupo Mosquitos Vetores: Endossimbiontes e Interação Patógeno-Vetor, Instituto René Rachou-Fiocruz, Belo Horizonte 30190-002, Brazil; thiagonp@hotmail.com (T.N.P.); fabiano.carvalho@fiocruz.br (F.D.C.)

2 Grupo Taxonomia de Flebotomíneos e Epidemiologia das Leishmanioses, Instituto René Rachou-Fiocruz, Belo Horizonte 30190-002, Brazil; jeronimomnr@hotmail.com

3 Department of Bioprocesses and Biotechnology, School of Agricultural Sciences, São Paulo State University (UNESP), Botucatu 18610-034, Brazil; vanessa.carvalho@unesp.br (V.R.d.C.); jayme.souza-neto@unesp.br (J.A.S.-N.)

4 School of Agricultural Sciences, Central Multiuser Laboratory, São Paulo State University (UNESP), Botucatu 18610-034, Brazil

5 Institute of Biotechnology, São Paulo State University (UNESP), Botucatu 18607-440, Brazil; jaquejaru@yahoo.com.br

* Correspondence: luciano.andrade@fiocruz.br

Citation: Pereira, T.N.; Carvalho, F.D.; Rugani, J.N.; de Carvalho, V.R.; Jarusevicius, J.; Souza-Neto, J.A.; Moreira, L.A. Mayaro Virus: The Potential Role of Microbiota and Wolbachia. Pathogens 2021, 10, 525. https://doi.org/10.3390/ pathogens 10050525

Academic Editor: Anna Honko

Received: 18 February 2021

Accepted: 19 April 2021

Published: 27 April 2021

Publisher's Note: MDPI stays neutral with regard to jurisdictional claims in published maps and institutional affiliations.

Copyright: (c) 2021 by the authors. Licensee MDPI, Basel, Switzerland. This article is an open access article distributed under the terms and conditions of the Creative Commons Attribution (CC BY) license (https:// creativecommons.org/licenses/by/ $4.0 /)$.

\begin{abstract}
The Mayaro virus (MAYV) is an arbovirus that circulates mainly in tropical forests or rural areas in Latin America and is transmitted mainly by Haemagogus mosquitoes. The objective of this study was to evaluate the vector competence, microbiome, and the presence of Wolbachia in three Aedes albopictus populations infected with MAYV. The vector competence was assessed based on viral infection and transmission by RT-qPCR. In addition, the microbiome was evaluated by amplification of the 16S rRNA V4 region and PCR to detect the presence of Wolbachia (strain wAlbA/wAlbB). Our results show that all three populations were susceptible to MAYV infection. The potential transmission of the MAYV was consistent in all populations of naïve mosquitoes injected (more than $50 \%$ ). The microbiome analysis revealed 118 OTUs (operational taxonomic unit) from the three populations, 8 phyla, 15 classes, 26 orders, 35 families, 65 genera, and 53 species. All populations had Pseudomonas and Wolbachia as predominant genera. There was no difference between the variables for MAYV and Wolbachia (wAlbA or wAlbB) in the abdomen. However, in the head + thorax samples at $14 \mathrm{dpi}$, there was a difference between the two populations, indicating a possible correlation between the presence of Wolbachia $(w \mathrm{AlbB})$ and infection. Overall, we show evidence that Ae. albopictus displays significant infection and transmission competence for the MAYV in the laboratory, and its bacterial microbiota play an important role in the host, mainly the strains of Wolbachia. The influence of the intestinal microbiota of Ae. albopictus is poorly known, and a better understanding of these interactions would open new perspectives for disease control through the manipulation of microbial communities. The exact contribution of this mosquito species to the transmission of the MAYV in the field remains to be confirmed.
\end{abstract}

Keywords: Mayaro virus; Aedes albopictus; vector competence; microbiota and Wolbachia

\section{Introduction}

Vector-borne diseases are among the main causes of human morbidity and mortality. Every year, more than one billion people are infected and more than one million people die from vector-borne diseases [1]. Annually, these diseases account for significant impacts to public health services and negatively impact development and economic growth [2].

The mosquito Aedes albopictus is native to the forests of Southeast Asia, where it is an important vector for different arboviruses, posing a potential risk to public health [3-5]. This invasive mosquito species was first recorded in Brazil in 1986 in the state of Rio de 
Janeiro [6]. Current data shows that Ae. albopictus is present in 25 out of 27 Brazilian states $[7,8]$.

For a long time, Ae. albopictus was considered by many authors as a species of relatively low importance in the transmission of pathogens to humans, minimizing their importance in public health issues. However, over the past years, many studies have demonstrated the vector competence of Ae. albopictus for arboviruses [9-13].

Important vector-borne diseases have re-emerged or spread to new parts of the world, and an example is the Mayaro virus (MAYV). This virus is an Alphavirus, member of the Togaviridae family, and is closely related to the Chikungunya virus (CHIKV) [14], with both displaying similar clinical symptoms in humans, including high fever, frontal headache, maculopapular eruption, photophobia, nausea, epigastric pain, myalgia, and severe arthralgia, which may persist for months or even years $[15,16]$. Given the high degree of similarity in symptoms caused by arboviruses, it is difficult to distinguish and diagnose the causative agents of infections in humans; this can ultimately lead to underestimation of the real prevalence and circulation of viruses, such as the MAYV, in the population $[17,18]$.

Several cases of the MAYV have occurred in different localities in Brazil, including the Northern, Northeastern, and Central West regions, with frequent occurrence in the states of Pará, Amazonas, Acre, and Mato Grosso [17,19-24]. Such notifications indicate the circulation of the MAYV and consequently reinforce the importance of mosquito vector competence studies.

The relationship between microbiota and vector competence is not fully understood; however, it is known that the natural bacterial microbiota has been shown to contribute to immunity, vector competence, and influence pathogen development $[25,26]$, as well as nutritional aspects [27]. Regarding the bacterial composition, a very important relationship with the endosymbiotic bacterium called Wolbachia pipientis needs mentioning. Wolbachia is a maternally inherited alphaproteobacterium estimated to infect up to $60 \%$ of arthropod species $[28,29]$. This bacterium is a promising biocontrol agent due to its ability to modulate replication of some arboviruses in Ae. Aegypti [30-32]. The mosquitoes Ae. albopictus are naturally infected with the Wolbachia strains $w \mathrm{AlbA}$ and/or wAlbB [33,34], which in some cases can modulate the vector competence of its hosts.

Thus, considering the contribution of microbiota in vector competence and the few studies related to the vector competence of Ae. albopictus for the MAYV, we have shown that Ae. albopictus of distinct field-derived populations display significant infection and transmission competence for the MAYV. Additionally, it was observed that the bacterial microbiota play an important role in the host, mainly when the strains of Wolbachia are present.

\section{Materials and Methods}

\subsection{Mosquito Rearing}

Ae. albopictus eggs were collected through ovitraps from the following states in Brazil: Minas Gerais (Belo Horizonte City $/ 19^{\circ} 52^{\prime} 12.4^{\prime \prime} \mathrm{S} 43^{\circ} 58^{\prime} 14.5^{\prime \prime}$ W), Rio de Janeiro (Rio de Janeiro City $/ 22^{\circ} 52^{\prime} 39.2^{\prime \prime} \mathrm{S} 43^{\circ} 14^{\prime} 25.4^{\prime \prime} \mathrm{W}$ ), and Santa Catarina (Tubarão City $/ 28^{\circ} 28^{\prime} 40.0^{\prime \prime} \mathrm{S}$ $\left.49^{\circ} 01^{\prime} 25.0^{\prime \prime} \mathrm{W}\right)$. All collections occurred in March 2017. The eggs were hatched at the Instituto René Rachou, Fiocruz/MG in a controlled insectary environment at $27 \pm 2{ }^{\circ} \mathrm{C}$, $\sim 82 \% \mathrm{RH}$ and $12 \mathrm{~h}$ light/dark regime. Larvae were fed with TetraMin Tropical (Tetra ${ }^{\circledR}$ fish food, Melle, Germany) ad libitum, and adults were given $10 \%$ sucrose solution ad libitum. Adult mosquitoes were visually screened to select only Ae. albopictus. Adult females were fed blood from a human blood bank (see mosquito infection) using an artificial water-jacketed membrane feeding apparatus for egg production. All experiments were performed using females from a colony derived from within no more than two generations of egg collection. 


\subsection{Virus}

The MAYV was maintained in the Ae. albopictus cell line (C6/36) in Leibowitz L-15 medium supplemented with $10 \%$ foetal calf serum at $28^{\circ} \mathrm{C}$. On the first mosquito infection replicate (A), the viral supernatant was harvested at 5 days after cell infection, with a viral titer of $1 \times 10^{9} \mathrm{PFU} / \mathrm{mL}$, and for the second mosquito infection replicate (B), it was harvested at 4 days after cell infection, with a viral titer of $6 \times 10^{9} \mathrm{PFU} / \mathrm{mL}$. Both viral batches were quantified after a freezing process.

\subsection{Mosquito Infection}

Through an artificial water-jacketed membrane feeding apparatus set up at $38^{\circ} \mathrm{C}$, 5-day-old mosquitoes were challenged with an infectious blood meal spiked with a cultured viral supernatant (two virus: one blood) for $45 \mathrm{~min}$. The human blood used in all experiments was obtained from a blood bank (Fundação Hemominas, Belo Horizonte, MG, Brazil), according to the terms of an agreement with Instituto René Rachou, Fiocruz/MG (OF.GPO/CCO agreement-Nr 224/16). Fully engorged females were separated on a cold Petri dish and maintained in cages with $10 \%$ sucrose solution ad libitum until collection. Whole mosquitoes were collected on different days post-infection (dpi) and stored at $-80^{\circ} \mathrm{C}$.

\subsection{Saliva Collection}

Fourteen dpi, mosquitoes were anaesthetized by $\mathrm{CO}_{2}$ exposure and kept on an ice plate while the wings and legs were removed. Each mosquito had its proboscis inserted into a $10 \mu \mathrm{L}$ pipette tip containing $10 \mu \mathrm{L}$ of a $1: 1$ solution of $30 \%$ sucrose and sterile fetal bovine serum for the salivation process [35]. After $30 \mathrm{~min}$, the contents of the tips were individually collected and stored at $-80^{\circ} \mathrm{C}$.

\subsection{Saliva Nanoinjection}

Eight samples of undiluted saliva from each Ae. albopictus population were individually injected ( $207 \mathrm{~nL}$ dose) into the pleural membranes of 15 naïve Ae. aegypti using the Nanoject II injector (Drummond Sci, Broomall, PA, USA). Five days after, whole nanoinjected mosquitoes were collected, and viral presence was determined by RT-qPCR analysis on an average of six mosquitoes per group. We used Ae. aegypti mosquitoes for saliva nanoinjection given their confirmation as good amplification hosts for this virus [13].

\subsection{RNA Extraction and Real-Time RT-qPCR}

Total RNA/DNA was extracted from the head + thorax of each individual female mosquito using the High Pure Viral Nucleic Acid Kit (Roche), following manufacturer's instructions. A specific set of primers and probes were used for the MAYV [36] and RPS17 [37].

To assess the presence of the MAYV (mosquito infection), total head + thorax RNA was used, whereas for transmission potential, the RNA was extracted from whole saliva-injected mosquitoes. RNA samples were quantified using the NanoDrop ${ }^{\mathrm{TM}} 2000$ spectrophotometer (Thermo Scientific, Walthman, MA, USA); all samples were diluted to $50 \mathrm{ng} / \mu \mathrm{L}$.

The thermocycling conditions were as follows: reverse transcription at $50{ }^{\circ} \mathrm{C}$ for $10 \mathrm{~min}$; RT inactivation/initial denaturation at $95^{\circ} \mathrm{C}$ for $30 \mathrm{~s}, 40$ cycles of $95^{\circ} \mathrm{C}$ for $5 \mathrm{~s}$ and $60{ }^{\circ} \mathrm{C}$ for $30 \mathrm{~s}$, followed by cooling at $37^{\circ} \mathrm{C}$ for $30 \mathrm{~s}$. The total reaction volume contained $10 \mu \mathrm{L}\left(5 \times\right.$ LightCycler $^{\circledR}$ Multiplex RNA Virus Master, Roche, Basel, Switzerland), $1 \mu \mathrm{M}$ primers and probe, and $125 \mathrm{ng}$ of RNA. The MAYV infection levels in mosquitoes were quantified by RT-qPCR using the LightCycler ${ }^{\circledR} 96$ (Roche, Basel, Switzerland).

The multiplex assay was performed with probe and primers specific for the MAYV: MayV-F $/ 5^{\prime} /$ GTG GTC GCA CAG TGA ATC TTTC $/ 3^{\prime}$ and MayV- R $/ 5^{\prime} /$ CAA ATG TCC ACC AGG CGA AG/3' and May-Probe 5'/FAM/ATG GTG GTA GGC TAT CCG ACA GGT C $/ 31 \mathrm{ABkFQ} / 3^{\prime}$ (36). For mosquito detection, the ribosomal gene S17 (RPS17) was used, and the probe and primers were 117S-F 5' /TCC GTG GTA TCT CCA TCA AGC 
T/3'/e 17S-R 5 $5^{\prime} /$ CAC TTC CGG CAC GTA GTT GTC $/ 3^{\prime}$ and probe $5^{\prime} /$ HEX/CAG GAG GAG GAA CGT GAG CGC AG/3B [37].

All head + thorax samples were tested in duplicate for the MAYV and analyzed using absolute quantification by serial dilutions of the target gene product (MAYV) cloned into the plasmid pGEMT-Easy (Promega, Madison, WI, USA), according to the manufacturer's instructions. The head + thorax samples were quantitatively evaluated, whereas whole mosquitoes (after saliva/nanoinjection procedure) were qualitatively evaluated. Negative and positive control samples were normalized and used to determine a threshold between samples.

\section{7. cDNA Synthesis}

For the assay of identification of Wolbachia and metagenomics, after total RNA extraction and quantification via NanoDrop, $1 \mu \mathrm{g}$ of total RNA was treated with DNAse enzyme (Promega, Madison, WI, USA). Then, the final product $(11 \mu \mathrm{L})$ was used for cDNA synthesis following the manufacturer's recommendations, via use of the enzyme M-MLV reverse transcriptase (Promega, Madison, WI, USA). At the end of the process, the cDNA was diluted (1:10) in water free of nucleases and stored at $-20^{\circ} \mathrm{C}$.

\subsection{Amplification of the $16 S$ rRNA V4 Region}

To determine the diversity of microbiota, 10 abdomens were used for each population (adult mosquitoes). For the polymerase chain reaction (PCR), primers specific to the hypervariable region $\mathrm{V} 4$ [38] for amplification of the $16 \mathrm{~S}$ rDNA gene were used, according to the methodology used by Caporaso [39]. Each sample was amplified with different forward primers (Supplementary Table S1). The generated libraries were purified with magnetic beads (AMPureAgencourt) and quantified in the QuantStudio 3 (Applied Biosystems) with the KapaSybrFast Universal qPCR Kit. The mean Ct values of each sample were adjusted to a concentration of $4.0 \mathrm{nM}$.

\subsection{Illumina Sequencing}

Next generation sequencing (NGS) was performed in the MiSeq Personal Sequencer (Illumina, San Diego, CA, USA) equipment of the Molecular Biology Laboratory, Clinical Hospital fromUNESP School of Medicine (Botucatu São Paulo) by metagenomic workflow with two MiSeq Reagent v2 kits (300 cycles). The data were pre-processed by the MiSeq Reporter software v.10.1.2.

\subsection{Sequencing Analysis}

The software CLC Microbial Genomics Module (Qiagen, Hilden, Germany) was used following the manual guidelines. For the pairing of reads, the parameters used were mismatch cost: 2 , minimum score: 8 , gap cost: 3 , and maximum unalignment and mismatches: 0, followed by setting the lengths of reads. Sample filtering was performed so that all samples had a minimum value of 100 reads and a minimum percentage of $50 \%$ away from the median. The operational taxonomic unit (OTU) clustering was done with the SILVA database, with $97 \%$ similarity between sequences and filter removal of OTUs of abundance less than $0.005 \%$.

\subsection{Identification of Wolbachia and Sequencing}

Mosquito (abdomen and head + thorax) cDNA $(20 \mathrm{ng} / \mu \mathrm{L})$ were used in PCR reactions for Wolbachia wAlbA and wAlbB genotyping. The primers $w$ AlbA F (5'-GTG TTG GTG CAG CGT ATG TC-3'), wAlbA R (5'-GCA CCA GTA GTT TCG CTA TC-3'), wAlbB F ( $5^{\prime}$ ACG TTG GTG GTG CAA CAT TTG-3'), and wAlbB R (5'-TAA CGA GCA CCA GCA TAA AGC-3')(34) (Zhou et al., 1998; Armbruster et al., 2003), which amplified a $187 \mathrm{bp}$ and $268 \mathrm{bp}$ fragment, respectively, were used in reactions containing $1.5 \mathrm{mM} \mathrm{MgCl}_{2}, 200 \mu \mathrm{M}$ dNTP mix (New England Biolabs, Ipswich, MA, USA), 5.0\% dimethyl sulfoxide (Invitrogen, Carlsbad, CA, USA), 1.5 units of platinum Taq DNA polymerase (Invitrogen, Carlsbad, 
CA, USA), 0.4 pmol of sense primer, and 0.4 pmol of antisense primer (IDT Technologies, Coralville, IA, USA). The cDNA amplification was performed in a thermal cycler using 40 cycles of denaturation at $94{ }^{\circ} \mathrm{C}$ for $45 \mathrm{~s}$, primer-specific annealing for $45 \mathrm{~s}\left(56{ }^{\circ} \mathrm{C}\right.$ for $w \mathrm{AlbA}$ and $59^{\circ} \mathrm{C}$ for $w \mathrm{AlbB}$ ) and extension at $72{ }^{\circ} \mathrm{C}$ for $45 \mathrm{~s}$, followed by one final extension at $72{ }^{\circ} \mathrm{C}$ for $5 \mathrm{~min}$. Amplification products were visualized on $2 \%$ agarose gels stained with ethidium bromide $(10 \mu \mathrm{g} / \mathrm{mL})$. Ten samples of each group showing the specific band for both $w \mathrm{AlbA}$ and $w \mathrm{AlbB}$ were sequenced by the Fiocruz sequencing platform (Sanger) to confirm species genotyping.

\subsection{Data Analysis}

The mosquito infection rate was analyzed with Person omnibus normality and D'Agostino tests. Fisher's exact test was then used to assess differences in viral prevalence. Comparisons were significant for $p$ values lower than 0.05 , and viral load data were compared through the Mann-Whitney U test. Pearson's Chi-squared test was used as an inferential test of the independence of two nominal variables (Wolbachia and MAYV). All analyses were performed by using Prism V 7.4 (GraphPad).

The CLC Microbial Genomics Module (Qiagen, Hilden, Germany) software was used to evaluate the microbiome, both $\alpha$-and $\beta$-diversity parameters. $\alpha$-diversity was calculated using the Simpson index, which considers richness, uniformity of samples and the 100 most abundant OTUs. The $\beta$-diversity analysis was used to compare the distances of the sequenced samples from each other in the intestinal microbiota composition. This analysis can estimate the differences of OTUs between the study samples. To estimate the differences, the UniFrac measure and Principal Coordinate Analysis (PCoA) were used for analysis visualization. To complete the $\beta$-diversity data, an analysis was performed using the CLC Microbial Genomics Module software. A phylogenetic OTU tree was constructed using the maximum likelihood method, which is based on the multiple sequence alignment by the MUSCLE (MUltiple Sequence Comparison and Log Expectation) software v.10.1.2.

\section{Results}

Our results showed significant effects on susceptibility/infection of the MAYV in all three Ae. albopictus populations for 7 and $14 \mathrm{dpi}$ (Figure 1). There was a statistically higher dissemination at $14 \mathrm{dpi}$ when compared to $7 \mathrm{dpi}$ only in Ae. albopictus from Santa Catarina (Fisher's exact test $p=0.0013$, odds ratio $0.2,95 \%$ CI, 0.1599-0.603).

The population from Santa Catarina showed the highest infection rate $(58.7 \%)$, followed by the population of Minas Gerais (56.6\%) and Rio de Janeiro (28.2\%). According to these results, we compared the proportion of infection among the groups, and the population from Rio de Janeiro was different than that from Santa Catarina (Fisher's exact test $p=0.0002$, odds ratio $0.2818,95 \%$ CI, $0.3520-0.7511$ ) and Minas Gerais (Fisher's exact test $p=0.0009$, odds ratio $0.3004,95 \% \mathrm{CI}, 0.4023-0.8225$ ).

The median (viral copies) detected in the head + thorax samples from the first replicate (Figure 1A) were $5.45 \times 10^{4}$ for the Santa Catarina, $5.52 \times 10^{4}$ for the Rio de Janeiro, and $6.12 \times 10^{3}$ for the Minas Gerais samples at $14 \mathrm{dpi}$. For the second replicate (Figure 2B), the median viral copies for Santa Catarina mosquitoes were $1.24 \times 10^{2}$ on $7 \mathrm{dpi}$ and $6.88 \times 10^{4}$ on $14 \mathrm{dpi}, 9.2 \times 10^{1}$ for Rio de Janeiro mosquitoes on $14 \mathrm{dpi}$, and $5.52 \times 10^{4}$ copies/head + thorax for Minas Gerais mosquitoes on $14 \mathrm{dpi}$.

To verify the occurrence of the MAYV in Ae. albopictus mosquito saliva, we added a virus amplification step in live naïve Ae. aegypti. The MAYV was detected in 26 out of 48 mosquitoes (54.1\%) that received saliva from mosquitoes from Santa Catarina (Figure 2A). When saliva originated from Rio de Janeiro mosquitoes, 27 out of 42 injected mosquitoes $(64.2 \%)$ became infected (Figure 2B). Saliva originating from mosquitoes from Minas Gerais was also able to infect most naïve mosquitoes (24/45; 53.3\%) (Figure 2C). Overall, $70 \%$ of all the injected saliva samples, irrespective of origin and nanoinjected mosquitoes, were able to infect Ae. aegypti mosquitoes through nanoinjection, and therefore 
proved to be infectious. The rate of infection/transmission of the MAYV, according to dpi, in each population and for both replicates are shown in Table 1.

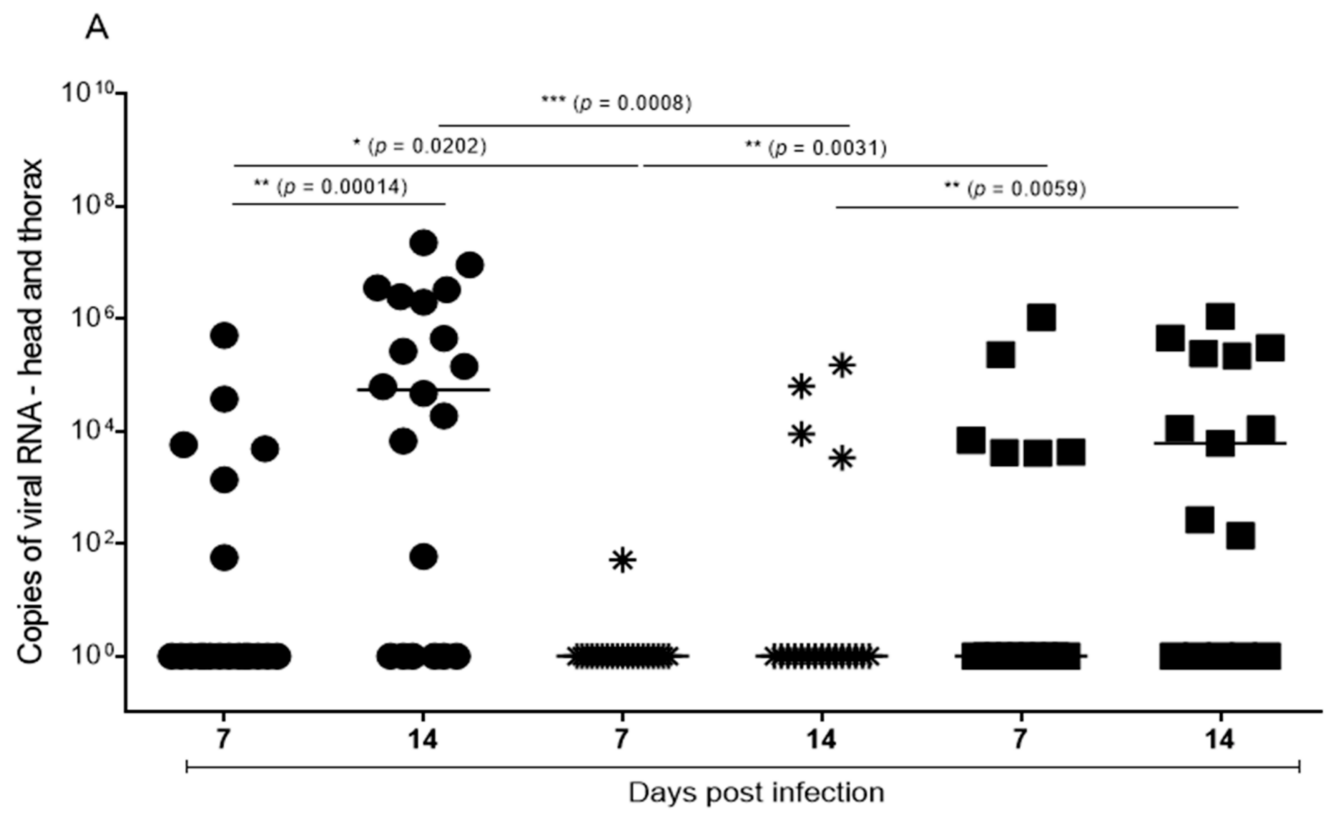

Aedes albopictus from Santa Catarina * Aedes albopictus from Rio de Janeiro Aedes albopictus from Minas Gerais

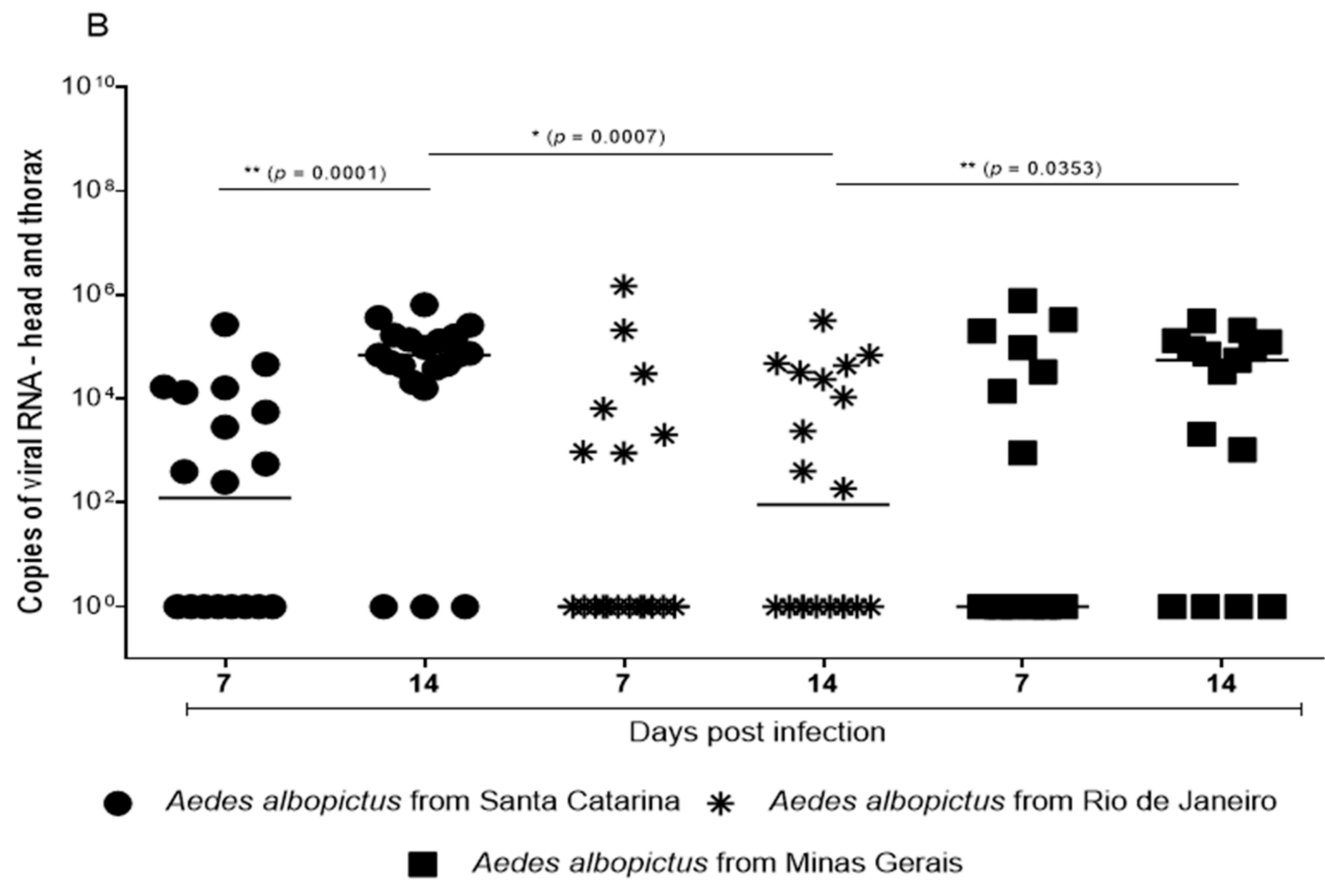

Figure 1. Viral infection rate. Each geometric format represents a single adult mosquito (f). Horizontal lines in black indicate the median absolute copy number of the Mayaro virus in each replicate group tested (A,B). The asterisks at the top represent the significance after analysis through the MannWhitney U-test $\left({ }^{*} p \leq 0.05 ;{ }^{* *} p \leq 0.01 ;{ }^{* * *} p \leq 0.001\right)$. This figure was generated from the methodology item: Section 2.3. 

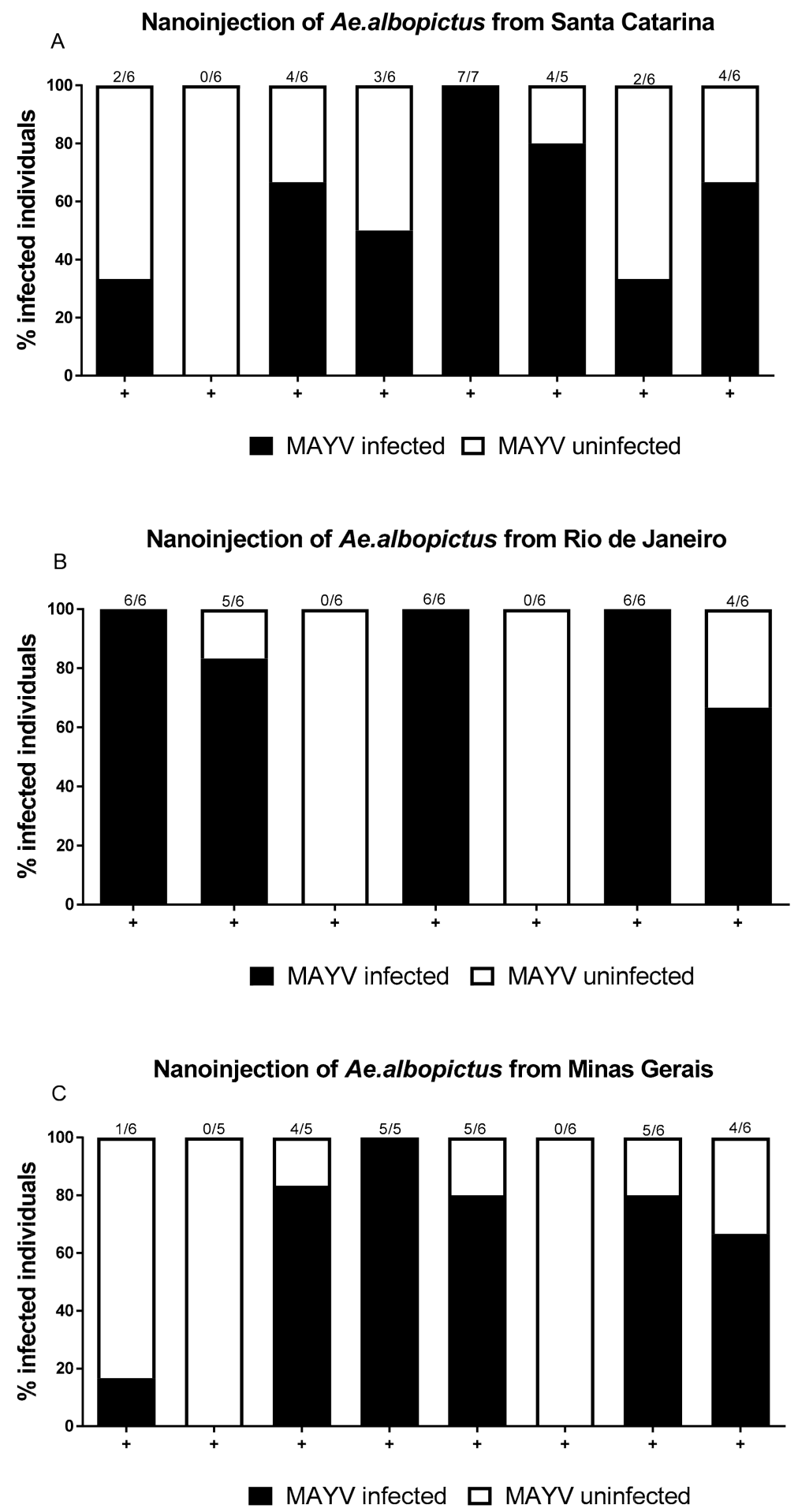

Figure 2. Nanoinjection of different infected saliva groups into naïve Aedes aegypti mosquitoes. The saliva was collected from orally infected Ae. albopictus with MAYV from Santa Catarina (A), Rio de Janeiro (B), and Minas Gerais (C) mosquitoes, followed by nanoinjection into Ae. aegypti naïve mosquitoes. Infected mosquitoes are shown in black and uninfected are depicted in white. Each column represents a single injected-saliva sample from positive head + thorax $(+)$. Each column represents a single saliva sample, and the number of transmission rate mosquitoes nanoinjected is given at the top of each bar. This figure was generated from the methodology item: Sections 2.4 and 2.5. 
Table 1. Aedes albopictus dissemination and transmission rates for Mayaro virus in two independent experiments.

\begin{tabular}{|c|c|c|c|c|}
\hline $\begin{array}{c}\text { Blood Meal } \\
\text { Titers (PFU/mL) }\end{array}$ & \multirow{3}{*}{$\begin{array}{c}\begin{array}{c}\text { Aedes albopictus } \\
\text { Population }\end{array} \\
\text { Santa Catarina }\end{array}$} & \multicolumn{2}{|c|}{$\begin{array}{c}\text { Head + Thorax } \\
\text { Dissemination Rate (\%) }\end{array}$} & \multirow[t]{2}{*}{$\begin{array}{l}\text { Transmission Rate } \\
\text { (Based on Saliva) }\end{array}$} \\
\hline \multirow{6}{*}{$1 \times 10^{9}$} & & $7 *$ & $30 \%$ & \\
\hline & & 14 * & $70 \%$ & \multirow{3}{*}{$\begin{array}{c}\text { Santa Catarina } \\
54.1 \%\end{array}$} \\
\hline & \multirow{2}{*}{ Rio de Janeiro } & 7 & $5 \%$ & \\
\hline & & 14 & $20 \%$ & \\
\hline & \multirow{2}{*}{ Minas Gerais } & 7 & $40 \%$ & \multirow{4}{*}{$\begin{array}{c}\text { Rio de Janeiro } \\
64.2 \%\end{array}$} \\
\hline & & 14 & $66.6 \%$ & \\
\hline \multirow{6}{*}{$6 \times 10^{9}$} & \multirow{2}{*}{ Santa Catarina } & 7 & $50 \%$ & \\
\hline & & 14 & $85 \%$ & \\
\hline & \multirow{2}{*}{ Rio de Janeiro } & 7 & $36.8 \%$ & \multirow{4}{*}{$\begin{array}{c}\text { Minas Gerais } \\
53.3 \%\end{array}$} \\
\hline & & 14 & $50 \%$ & \\
\hline & \multirow{2}{*}{ Minas Gerais } & 7 & $46.6 \%$ & \\
\hline & & 14 & $73.3 \%$ & \\
\hline
\end{tabular}

Regarding the microbiome analysis, 118 OTUs were obtained from the three populations; however, the microbiota of mosquitoes was quite similar between the three groups, and a low diversity of bacteria was observed at all levels of taxonomic classification. The most predominant bacteria belonged to the order Ricketesiales, with frequencies higher than $80 \%$ in all samples. This order is represented mainly by the genus Wolbachia. The results indicated that the locality did not influence the richness of the microbiota and the presence of Wolbachia (Supplementary Table S2). Most mosquitoes presented with the genus Wolbachia, followed by the genera Pseudomonas and Acinetobacter (Figure 3).

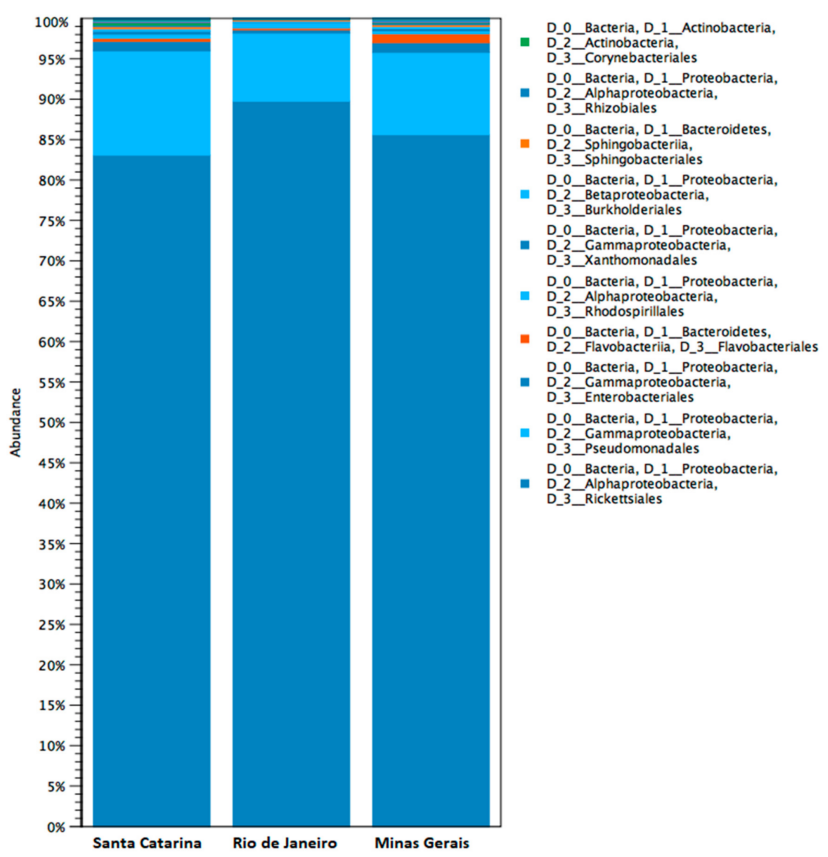

Figure 3. Bar graph generated by the analysis of relative abundance at Order level. The vertical axis shows the relative abundance of each bacterial Order, while the horizontal axis shows the locations of the collected mosquitoes. This figure was generated from the methodology item: Section 2.10. 
Analyses comparing different parameters, such as region and infection/non-infection of mosquitoes, did not show significant differences between groups. In addition, $\alpha$ - and $\beta$ diversity analyses were performed that measured the quantity and abundance of species in homogeneous habitats or different habitats. The sequencing coverage was estimated using rarefaction curves, which starts at approximately 300 reads, indicating that the sequencing was performed at a level good enough to estimate the microbial diversity of the analyzed samples. In the $\beta$-diversity analysis, the sample groups were not distant from each other, so the formation of clusters was not observed (Figure 4). To complement the $\beta$-diversity data, a PERMANOVA analysis was performed, enabling to compare two groups at a time. The significant difference between the groups of samples analyzed was not confirmed, and this is likely due to the predominance of the Wolbachia bacteria in the microbiota of the mosquitoes.

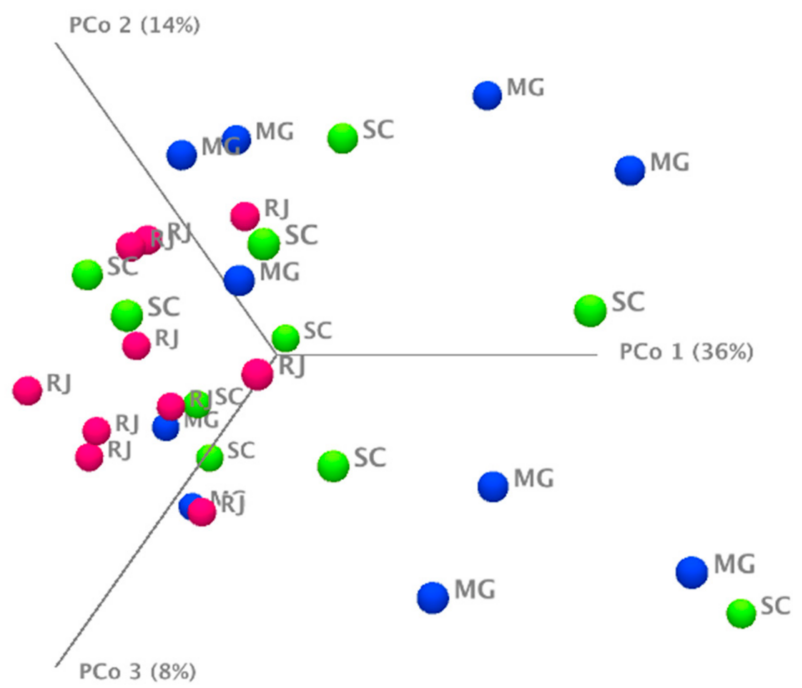

Figure 4. Beta diversity analysis by location. MG: Minas Gerais (blue), SC: Santa Catarina (green), and RJ: Rio de Janeiro (pink). This figure was generated from the methodology item: Section 2.10.

The presence of Wolbachia (wAlbA and wAlbB strains) in mosquitoes (in head + thorax) exhibited higher density at $7 \mathrm{dpi}$ in comparison to $14 \mathrm{dpi}$ (Figure 5A). All populations were statistically different (Fisher's exact test) between 7 and $14 \mathrm{dpi}-$ Santa Catarina $p=0.0067$, odds ratio 3.889, 95\% CI, 1.5320-9.870; Rio de Janeiro $p<0.0001$, odds ratio $16.07,95 \%$ CI, 5.171-49.95; and Minas Gerais $p=0.0169$, odds ratio 4.297, 95\% CI, 1.412-13.07.

Overall, the wAlbA strain was less present than the wAlbB strain. For the Rio de Janeiro population, its titer exhibited an opposite scenario in relation to the $w$ AlbB strain, when titers increased at 14 dpi (Fisher's exact test $p=0.0287$, odds ratio $0.1071,95 \%$ CI, 0.01266-0.9096). Regarding the presence of both the $w \mathrm{AlbA}$ and $w \mathrm{AlbB}$ strains in the same mosquito, this was more consistent at $14 \mathrm{dpi}$ for mosquitoes from Santa Catarina and Minas Gerais.

The presence of Wolbachia (wAlbA and wAlbB strains) in the abdomens of mosquitoes was greater than $97 \%$ in all three populations, as well as the presence of $w \mathrm{AlbA}$ and $w \mathrm{AlbB}$ strains in the same mosquito (Figure $5 \mathrm{~B}$ ). The population was not statistically different (Fisher's exact test) between 7 and 14 dpi.

When correlating the presence of Wolbachia with the MAYV infection rate, we observed that there was dependence between the $w$ AlbB strain at $7 \mathrm{dpi}$ for Rio de Janeiro (Pearson $x^{2}=0.0237 ; \operatorname{Pr}=0878$ ) and Santa Catarina (Pearson $x^{2}=0.1270 ; \operatorname{Pr}=0722$ ) populations, meaning that the greater the presence of this strain is, the lower the mosquito infection rate (Figure 6). 

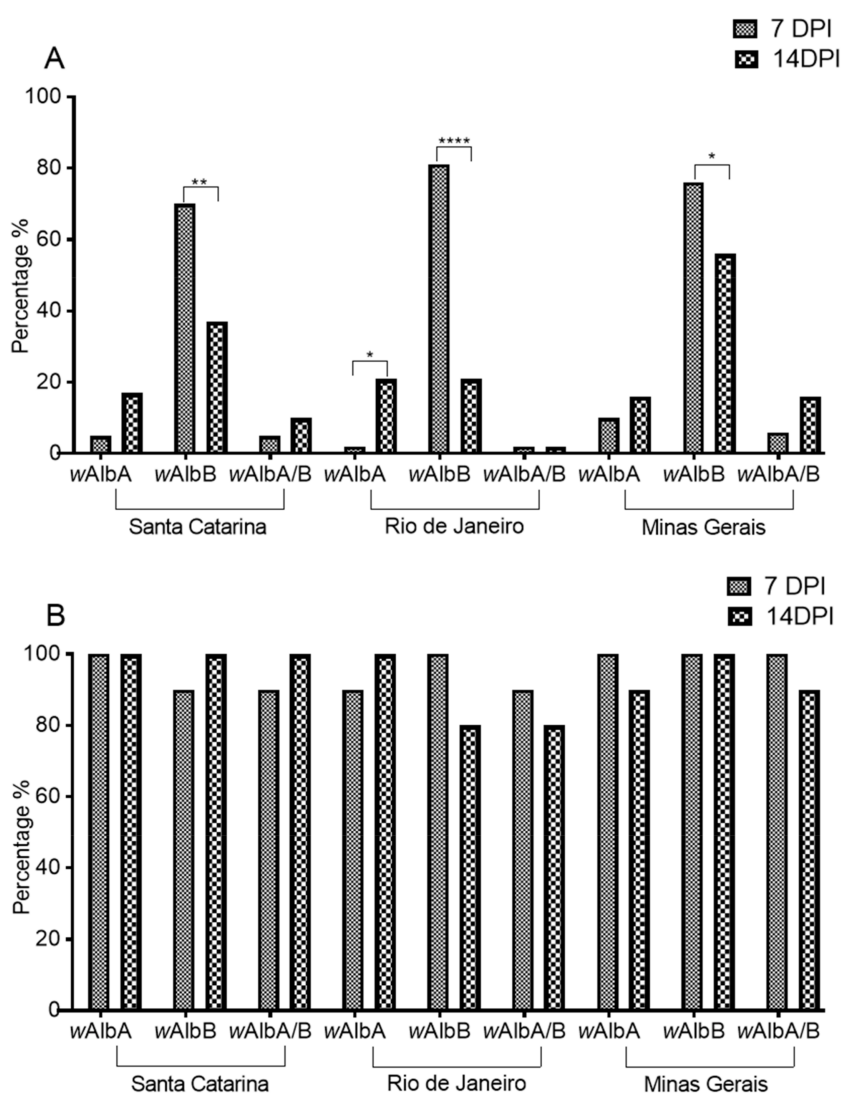

Figure 5. Presence of Wolbachia strains (wAlbB, $w \mathrm{AlbB}$, and $w \mathrm{AlbA} / \mathrm{B})$ in Aedes albopictus mosquitoes at 7 and 14 dpi after Mayaro virus infection-(A) head + thorax samples and (B) abdomen samples. A-The asterisks at the top represent the significance after analysis through the Mann-Whitney U-test $\left({ }^{*} p \leq 0.05 ;{ }^{* *} p \leq 0.01 ;{ }^{* * * *} p \leq 0.0001\right)$. B-No statistical difference (Fisher's exact test). This figure was generated from the methodology item: Section 2.11 .

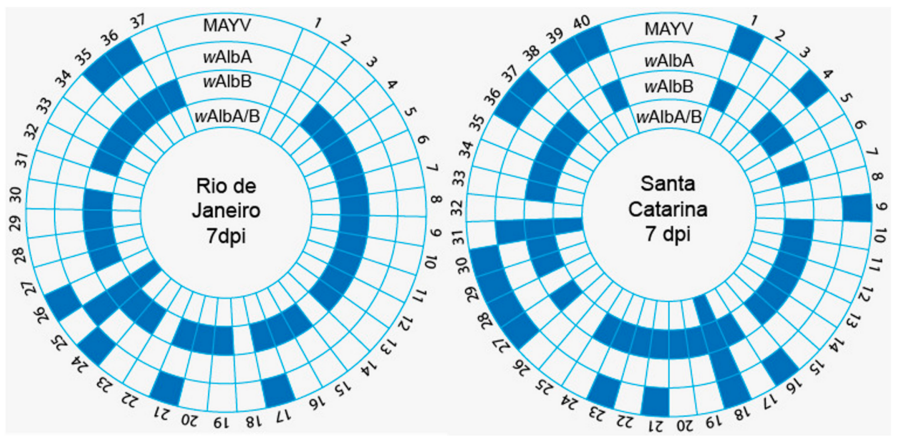

Figure 6. Relationship between Mayaro virus and Wolbachia strains in the Aedes albopictus at 7 dpi. Positive mosquito sample (blue) and negative (white). This figure was generated from the methodology item: Section 2.11.

\section{Discussion}

The emergence and re-emergence of arboviruses, such as Zika virus (ZIKV), yellow fever, and CHIKV has leveraged the number of studies focusing on understanding the whole of disease vectors, such as Ae. aegypti and Ae. albopictus, in the transmission potential for these viruses. To date, many authors have suggested that Ae. albopictus may play a role in the transmission of these distinct pathogens worldwide [10,11]. However, little is known about the susceptibility status of this mosquito species for the MAYV. 
Our results confirm that three geographically distinct Ae. albopictus populations from Brazil are susceptible to MAYV infection in the laboratory. Among the three populations, mosquitoes from Rio de Janeiro displayed lower rates of disseminated infection (around $50 \%$ less) in comparison to mosquitoes from the other two localities.

There are several potential reasons for this low rate of disseminated infection in the population of Ae. albopictus from Rio de Janeiro, including: (1) the anatomic barriers of the insect can determine the efficiency of the infection in the vector [40]; (2) the presence of symbiotic bacteria bearing antiviral genes [41] that can stimulate the mosquito's immune system or that compete for resources with the virus; (3) inducing immune response [12], either by bacteria or viruses; and (4) the geographical origin of the mosquito may also affect its vector competence, since different genotype/genotype interactions between the virus and vector may occur [42-44].

It is worth noting that sporadic/frequent contact between the vector and virus might induce a change in overall vector competence, as distinct studies have shown that the re-emergence of CHIKV (another arbovirus from the Togaviridae family) may have been facilitated by the genetic adaptation of the virus to the Ae. albopictus vector $[45,46]$.

In both our replicates, it was possible to observe that Santa Catarina mosquitoes had a median viral load of $10^{4}$ on $14 \mathrm{dpi}$, whereas it was $10^{3}$ for Minas Gerais and $10^{1}$ copies/head + thorax for Rio de Janeiro mosquitoes. However, it is noteworthy that, when analyzed at the individual level, many mosquitoes had a median infection intensity above $10^{5}$ viral copies, depicting a relevant susceptibility/interaction with the MAYV.

There is some evidence/speculation that Ae. albopictus have a satisfactory infection/dissemination and a large transmission capacity for the MAYV [36,47-49]. Wiggins et al. 2018 [47] observed in an oral infection assay that Ae. albopictus mosquitoes had a significantly higher infection rate when compared to that of Ae. aegypti mosquitoes. Their results are like those observed for our populations from Santa Catarina and Minas Gerais.

Diop et al. 2019 [12] observed increased expression levels of the type C1 gene (NPC1gene responsible for facilitating the infection of mosquitoes when infected with dengue) in infected Ae. albopictus mosquitoes, but not in Ae. aegypti mosquitoes. The differences in these levels of gene expression during MAYV infection could explain the variation in vector competence. We have tested the expressions of NPC1 and ML26A genes for Ae. albopictus and Ae. aegypti (control group); however, the expression of these genes was insignificant when compared to Diop et al. 2019 [12]. One possible explanation for this difference was the age of the mosquitoes. Diop et al. 2019 [12] used 3 dpi mosquitoes, while we used 7 dpi mosquitoes in our analysis.

To the best of our knowledge, there are few studies addressing the vector competence of Brazilian Ae. albopictus mosquitoes for the MAYV [50,51]. Smith and Francy 1991 [50] showed that, when these mosquitoes were fed viraemic hamster blood, the infection frequency ranged from $9 \%$ to $16 \%$. The authors concluded that their mosquito population was mostly refractory to MAYV infection. Already, in a more recent study, Pereira et al. 2020 [51] suggested that these mosquitoes could play a significant role in the transmission of the MAYV, since this species showed significant vector competence for the MAYV under laboratory conditions. In our case, our results are in line with the latest study.

Smith and Francy 1991 [50] noted in their study that approximately half of the mosquitoes infected with viraemic hamster blood were able to transmit the MAYV when their saliva was tested in capillary tubes. Their results were very similar to our results when we used mosquitos from Rio de Janeiro, where we observed a low virus dissemination rate but a high transmission for the MAYV (over 50\%). On the other hand, transmission results for populations from Santa Catarina and Minas Gerais were like Wiggins et al. 2018 [47] (38-76\%) and Pereira et al. 2020 [51] (71.1\%).

The bacterial microbiota analysis showed Wolbachia as the most abundant bacteria for all Ae. albopictus populations, constituting $>80 \%$ bacterial abundance. Following this analysis, using diagnostic primers for Wolbachia, two strains of Wolbachia (wAlbA and wAlbB) were detected. Wang et al. 2018 [52] observed that Wolbachia was extremely 
common in adult Ae. albopictus mosquitoes, constituting $>50 \%$ bacterial abundance, with the presence of both strains. This bacterium can cause some alterations in Ae. albopictus mosquitoes, such as reduced mosquito lifespan, cytoplasmic incompatibility, and vector competence to viruses $[53,54]$.

Rossi et al. 2015 [55] described a mutual exclusion between Wolbachia and Asaia in Aedes and Anopheles mosquitoes, which may explain why our mosquito samples exhibited a low abundance of Asaia (2 out of 30 samples) and very high abundance of Wolbachia (all 30 samples). Consistent with our results, the same pattern was observed by Wang et al. 2018 [52].

Besides Wolbachia, other bacteria such as Chromobacteria, Proteus or Paenibacillus have been related with the inhibition or enhancement of viruses [56,57]. However, in our study, in addition to Wolbachia, only Proteus was found, with the latter also being known to inhibit DENV-2 when administered to mosquitoes in the blood meal [58].

Consistent with our results, the high prevalence of Acinetobacter has been previously reported in Ae. Albopictus [59], as being involved in blood digestion. Enterobacter and Acinetobacter act as an attractant to gravid females and are known to play important roles in the parasite-vector interaction [60].

When correlating the presence of Wolbachia with the infection rate of the MAYV, we observed that there was a correlation between the wAlbB strain at 14 dpi for Santa Catarina and Rio de Janeiro mosquitoes (i.e., the greater the presence of this strain is, the lower the mosquito infection rate). The blocking effect of Wolbachia wAlbB strain seems to depend on the interaction between the host and pathogen. Studies have shown that the wAlbB strain in A. gambiae inhibits Plasmodium falciparum, but for P. berghei, the infection is exacerbated [61]. The relationship between the $w \mathrm{AlbB}$ strain and the Culex tarsalis mosquito increases infection with the West Nile virus [62] and blocks the transmission of dengue [56] and CHIKV [63].

In Ae. aegypti mosquitoes, the introduction of the wAlbB strain reduces the transmission of dengue and ZIKV [64], and it has been observed that this strain is more heat stable, indicating that it may be a promising tool in countries with elevated temperatures [65].

Although no correlation was observed in our experiments with the wAlbA strain and MAYV infection, it is known that, when this strain was introduced into Ae. aegypti mosquitoes, it had higher tissue distribution and higher densities in somatic tissues compared to those in the $w \mathrm{AlbB}$ strain, suggesting that this strain may strongly inhibit viruses [66]. Studies have shown the viral blocking capacity of the wAlbA strain in Ae. aegypti mosquitoes, both via intrathoracic nanoinjection of ZIKV and dengue and oral feeding with ZIKV [42]. For the Semliki Forest virus, through thoracic injection, no reduction in copies of the viral genome was detected compared to controls without Wolbachia [66].

One possible hypothesis for the higher presence of the wAlbB strain at $7 \mathrm{dpi}$ and low presence at $14 \mathrm{dpi}$ can be correlated to a number of factors such as lipids, as neither Wolbachia nor the virus have the necessary machinery to produce this nutrient, therefore, depending on the host [67], virus and wAlbB competition, membrane synthesis, and nucleic acid production pathways, for example. The Wolbachia mechanisms are not fully understood, the role of Wolbachia-induced innate immunity priming in pathogen interference is still an object of debate however clearer picture starts to emerge. Some hypotheses suggest that Wolbachia depend on host nutrients such as amino acids and lipids [68-70], thus being able to create a competition with viruses for subverting the same resources.

In Ae. aegypti mosquitoes, studies of the $w \mathrm{AlbB}$ strain showed that this bacterium was able to block dengue as effectively as the $w$ Mel strain, and the characterization of life history traits showed the $w$ AlbB strain resulted in minimal host fitness costs [71,72]. Flores et al. 2020 [73] measured the susceptibility to dengue infection of Ae. aegypti lines infected with different Wolbachia strain. For the wAlbB strain, only a blockade of intermediate degree was observed, such as that seen with abdominal infections in the oral feeding experiments. Mechanistically, the authors suggest that this may indicate differences in efficacy between 
strains and tissue type. However, it is difficult to compare studies, since the Wolbachia densities and tropism may underlie the observed differences.

Studies on different Wolbachia strains can direct and add to the list the strains that have potential as tools for use in arbovirus control, so it is important that we understand the relationship that transinfections (technique that allows the insertion of a strain into an unnatural host) may exert on different hosts.

The interaction of the MAYV and Ae. albopictus suggests a potential risk of this vector to public health. This becomes even more relevant given the detection of MAYV-positive sera in animals from a wide variety of taxa $[17,74]$, combined with the fact that Ae. albopictus are known to be opportunistic mosquitoes, displaying a broad range of hosts on which it feeds, making this vector a potential bridge by which spillover events can occur.

Together, our data show that, regardless of the population, Ae. albopictus mosquitoes from distinct regions of Brazil have high susceptibility and vector competence for the MAYV, which may ultimately contribute to the persistence and spread of this specific virus in the field. Finally, we need to stress that these experiments were performed under optimal controlled laboratory conditions; as such, the exact contribution of this mosquito species in the transmission of the MAYV in the field remains to be confirmed, as well as the real contribution of the $w \mathrm{AlbA} / \mathrm{B}$ strain in blocking the MAYV.

Supplementary Materials: The following are available online at https:/ / www.mdpi.com/article/10 .3390 / pathogens10050525/s1, Table S1: Primers used in the metagenomics assay, Table S2: Statistical analyses of the Aedes sp. Microbiome from different locality-PERMANOVA analysis (D_0 UniFrac).

Author Contributions: T.N.P., F.D.C., and L.A.M. contributed to the conception and design of all the experiments. T.N.P., F.D.C., J.N.R., J.J., and V.R.d.C. were involved in the performance of the experiments. T.N.P. and V.R.d.C. analyzed the data and T.N.P. drafted the manuscript. L.A.M., F.D.C., and J.A.S.-N. supervised the research and edited the final version of the manuscript. All authors have read and agreed to the published version of the manuscript.

Funding: This work was supported by FAPEMIG (APQ-00913-16, APQ-02760-17), CNPq, Coordenação de Aperfeiçoamento de Pessoal de Nível Superior-Brasil (CAPES)-Finance Code 001, São Paulo Research Foundation (FAPESP) (grants \# 2013/11343-6 and 2016/16952-9), INCT/FAPERJ (E-16/2014) and, indirectly, by the World Mosquito Program.

Institutional Review Board Statement: Not applicable.

Informed Consent Statement: Not applicable.

Data Availability Statement: The data presented in this study are available in the article and supplementary material.

Acknowledgments: We wish to thank Dra. Ana Maria Bispo de Filippis (IOC -FIOCRUZ) for donating the MAYV and Marco Antônio Silva Campos and their team, who provided infrastructure in the Laboratório de Imunologia de Doenças Virais (IRR-FIOCRUZ) for viral culture. We are also thankful to the Belo Horizonte Town Hall, Universidade Federal de Minas Gerais, and Universidade do Sul de Santa Catarina who helped in collecting the eggs. We also acknowledge Heverton L.C. Dutra for critical reading of the manuscript.

Conflicts of Interest: The authors declare no conflict of interest.

\section{References}

1. WHO. 2020. Available online: https://www.who.int/news-room/fact-sheets/detail/v (accessed on 4 January 2021).

2. Campbell-Lendrum, D.; Manga, L.; Bagayoko, M.; Sommerfeld, J. Climate change and vector-borne diseases: What are the implications for public health research and policy? Philos. Trans. R. Soc. B Biol. Sci. 2015, 370, 20130552. [CrossRef] [PubMed]

3. Gratz, N.G. Critical review of the vector status of Aedes albopictus. Med. Veter. Entomol. 2004, 18, 215-227. [CrossRef] [PubMed]

4. Paupy, C.; Delatte, H.; Bagny, L.; Corbel, V.; Fontenille, D. Aedes albopictus, an arbovirus vector: From the darkness to the light. Microbes Infect. 2009, 11, 1177-1185. [CrossRef] [PubMed]

5. Weaver, S.C.; Reisen, W.K. Present and future arboviral threats. Antivir. Res. 2010, 85, 328-345. [CrossRef]

6. Forattini, O.P. Identification of Aedes (Stegomyia) albopictus (Skuse) in Brazil. Rev. Saude Publica 1986, 20, 244-245. [CrossRef] 
7. Pancetti, F.G.M.; Honório, N.A.; Urbinatti, P.R.; Lima-Camara, T.N. Twenty-eight years of Aedes albopictus in Brazil: A rationale to maintain active entomological and epidemiological surveillance. Rev. Soc. Bras. Med. Trop. 2015, 48, 87-89. [CrossRef]

8. Saraiva, J.F.; Maitra, A.; Galardo, A.K.R.; Scarpassa, V.M. First record of Aedes (Stegomyia) albopictus in the state of Amapá, northern Brazil. Acta Amaz. 2019, 49, 71-74. [CrossRef]

9. Medlock, J.; Hansford, K.; Versteirt, V.; Cull, B.; Kampen, H.; Fontenille, D.; Hendrickx, G.; Zeller, H.; Van Bortel, W.; Schaffner, F. An entomological review of invasive mosquitoes in Europe. Bull. Entomol. Res. 2015, 105, 637-663. [CrossRef]

10. Zimler, A.R.; Alto, B.W. Florida Aedes aegypti (Diptera: Culicidae) and Aedes albopictus Vector Competency for Zika Virus. J. Med. Entomol. 2019, 56, 341-346. [CrossRef]

11. Gutiérrez-López, R.; Al., R.G.-L.E.; Ciota, A.T.; Montalvo, T.; La Puente, J.M.-D.; Gangoso, L.; Figuerola, J.; Kramer, L.D. Vector Competence of Aedes caspius and Ae. albopictus Mosquitoes for Zika Virus, Spain. Emerg. Infect. Dis. 2019, 25, 346-348. [CrossRef]

12. Diop, F.; Alout, H.; Diagne, C.T.; Bengue, M.; Baronti, C.; Hamel, R.; Talignani, L.; Liegeois, F.; Pompon, J.; Vargas, R.E.M.; et al. Differential Susceptibility and Innate Immune Response of Aedes aegypti and Aedes albopictus to the Haitian Strain of the Mayaro Virus. Viruses 2019, 11, 924. [CrossRef]

13. Pereira, T.N.; Rocha, M.N.; Sucupira, P.H.F.; Carvalho, F.D.; Moreira, L.A. Wolbachia significantly impacts the vector competence of Aedes aegypti for Mayaro virus. Sci. Rep. 2018, 8, 1-9. [CrossRef]

14. Vasconcelos, P.F.; Calisher, C.H. Emergence of Human Arboviral Diseases in the Americas, 2000-2016. Vector-Borne Zoonotic Dis. 2016, 16, 295-301. [CrossRef]

15. Azevedo, R.S.; Silva, E.V.; Carvalho, V.L.; Rodrigues, S.G.; Neto, J.P.N.; Monteiro, H.A.; Peixoto, V.S.; Chiang, J.O.; Nunes, M.R.; Vasconcelos, P.F. Mayaro Fever Virus, Brazilian Amazon. Emerg. Infect. Dis. 2009, 15, 1830-1832. [CrossRef]

16. Lucas, D.; Esposito, A.; Antonio, B. Review article Will Mayaro virus be responsible for the next outbreak of an arthropod-borne virus in Brazil? Braz. J. Infect. Dis. 2017, 21, 540-544.

17. Zuchi, N.; Heinen, L.B.D.S.; Dos Santos, M.A.M.; Pereira, F.C.; Slhessarenko, R.D. Molecular detection of Mayaro virus during a dengue outbreak in the state of Mato Grosso, Central-West Brazil. Memórias do Inst. Oswaldo Cruz 2014, 109, 820-823. [CrossRef]

18. De Oliveira Mota, M.T.; Ribeiro, M.R.; Vedovello, D.; Nogueira, M.L. Mayaro virus: A neglected arbovirus of the Americas. Future Virol. 2015, 10, 1109-1122. [CrossRef]

19. Vasconcelos, P.F.D.C.; Rosa, A.P.D.; Dégallier, N.; Rosa, J.F.S.T.D.; Pinheiro Filho, F.D.P. Clinical and ecoepidemiological situation of human arboviruses in Brazilian Amazonia. Cienc. Cult. 1992, 44, 117-124. Available online: http:/ /horizon.documentation.ird. $\mathrm{fr} /$ exl-doc/pleins_textes/pleins_textes_6/b_fdi_33-34/38273.pdf (accessed on 4 January 2021).

20. Figueiredo, R.M.P.D.; Thatcher, B.D.; Lima, M.L.D.; Almeida, T.C.; Alecrim, W.D.; Guerra, M.V.D.F. Doenças exantemáticas e primeira epidemia de dengue ocorrida em Manaus, Amazonas, no período de 1998-1999. Rev. Soc. Bras. Med. Trop. 2004, 37, 476-479. [CrossRef]

21. Silva-Nunes, M.D.; Malafronte, R.D.S.; Luz, B.D.A.; Souza, E.A.D.; Martins, L.C.; Rodrigues, S.G.; Chiang, J.O.; Vasconcelos, P.F.D.C.; Muniz, P.T.; Ferreira, M.U. The Acre Project: The epidemiology of malaria and arthropod-borne virus infections in a rural Amazonian population. Cad. Saude Publica 2006, 22, 1325-1334. Available online: http:/ /www.scielo.br/scielo.php?script= sci_arttext\&pid=S0102-311X2006000600021\&lng=en\&tlng=en (accessed on 6 January 2021). [CrossRef]

22. Mourão, M.P.G.; Bastos, M.D.S.; De Figueiredo, R.P.; Gimaque, J.B.L.; Galusso, E.D.S.; Kramer, V.M.; De Oliveira, C.M.C.; Naveca, F.G.; Figueiredo, L.T.M. Mayaro Fever in the City of Manaus, Brazil, 2007-2008. Vector-Borne Zoonotic Dis. 2012, 12, 42-46. [CrossRef] [PubMed]

23. Tavares-Neto, J.; Freitas-Carvalho, J.; Nunes, M.R.T.; Rocha, G.; Rodrigues, S.G.; Damasceno, E.; Darub, R.; Viana, S.; Vasconcelos, P.F.D.C. Pesquisa de anticorpos contra arbovírus e o vírus vacinal da febre amarela em uma amostra da população de Rio Branco, antes e três meses após a vacina 17D. Rev. Soc. Bras. Med. Trop. 2004, 37, 1-6. [CrossRef]

24. Brunini, S.; França, D.D.S.; Silva, J.B.; Silva, L.N.; Silva, F.P.A.; Spadoni, M.; Rezza, G. High Frequency of Mayaro Virus IgM among Febrile Patients, Central Brazil. Emerg. Infect. Dis. 2017, 23, 1025-1026. [CrossRef] [PubMed]

25. Engel, P.; Moran, N.A. The gut microbiota of insects-diversity in structure and function. FEMS Microbiol. Rev. 2013, 37, 699-735. [CrossRef] [PubMed]

26. Jupatanakul, N.; Sim, S.; Dimopoulos, G. The Insect Microbiome Modulates Vector Competence for Arboviruses. Viruses 2014, 6, 4294-4313. [CrossRef] [PubMed]

27. Coon, K.L.; Vogel, K.J.; Brown, M.R.; Strand, M.R. Mosquitoes rely on their gut microbiota for development. Mol. Ecol. 2014, 23, 2727-2739. [CrossRef] [PubMed]

28. Hilgenboecker, K.; Hammerstein, P.; Schlattmann, P.; Telschow, A.; Werren, J.H. How many species are infected with Wolbachia? A statistical analysis of current data. FEMS Microbiol. Lett. 2008, 281, 215-220. [CrossRef]

29. Weinert, L.A.; Araujo-Jnr, E.V.; Ahmed, M.Z.; Welch, J.J. The incidence of bacterial endosymbionts in terrestrial arthropods. Proc. R. Soc. B Boil. Sci. 2015, 282, 20150249. [CrossRef]

30. Bian, G.; Xu, Y.; Lu, P.; Xie, Y.; Xi, Z. The Endosymbiotic Bacterium Wolbachia Induces Resistance to Dengue Virus in Aedes aegypti. PLoS Pathog. 2010, 6, e1000833. [CrossRef]

31. Schultz, M.J.; Connor, J.H.; Frydman, H.M. Group B Wolbachia Strain-Dependent Inhibition of Arboviruses. DNA Cell Biol. 2018, 37, 2-6. [CrossRef] 
32. Rocha, M.N.; Duarte, M.M.; Mansur, S.B.; Silva, B.D.M.; Pereira, T.N.; Adelino, T.É.R.; Giovanetti, M.; Alcantara, L.C.J.; Santos, F.M.; de Melo Costa, V.R.; et al. Pluripotency of wolbachia against arboviruses: The case of yellow fever. Gates Open Res. 2019, 3, 1-27. [CrossRef]

33. Sinkins, S.P.; Braig, H.R.; O'Neill, S.L. Wolbachia superinfections and the expression of cytoplasmic incompatibility. Proc. R. Soc. B Boil. Sci. 1995, 261, 325-330. [CrossRef]

34. Zhou, W.; Rousset, F.; O'Neill, S. Phylogeny and PCR-based classification of Wolbachia strains using wsp gene sequences. Proc. R. Soc. B Boil. Sci. 1998, 265, 509-515. [CrossRef]

35. Dutra, H.L.C.; Rocha, M.N.; Dias, F.B.S.; Mansur, S.B.; Caragata, E.P.; Moreira, L.A. Wolbachia Blocks Currently Circulating Zika Virus Isolates in Brazilian Aedes aegypti Mosquitoes. Cell Host Microbe 2016, 19, 771-774. [CrossRef]

36. Long, K.C.; Tesh, R.B.; Higgs, S.; Hausser, N.L.; Thangamani, S.; Kochel, T.J.; Ziegler, S.A. Experimental Transmission of Mayaro Virus by Aedes aegypti. Am. J. Trop. Med. Hyg. 2011, 85, 750-757. [CrossRef]

37. Moreira, L.A.; Iturbe-Ormaetxe, I.; Jeffery, J.A.; Lu, G.; Pyke, A.T.; Hedges, L.M.; Rocha, B.C.; Hall-Mendelin, S.; Day, A.; Riegler, M.; et al. A Wolbachia Symbiont in Aedes aegypti Limits Infection with Dengue, Chikungunya, and Plasmodium. Cell 2009, 139, 1268-1278. [CrossRef]

38. Yatsunenko, T.; Rey, F.E.; Manary, M.J.; Trehan, I.; Dominguez-Bello, M.G.; Contreras, M.; Magris, M.; Hidalgo, G.; Baldassano, R.N.; Anokhin, A.P.; et al. Human gut microbiome viewed across age and geography. Nature 2012, 486, 222-227. [CrossRef]

39. Caporaso, J.G.; Lauber, C.L.; Walters, W.A.; Berg-Lyons, D.; Huntley, J.; Fierer, N.; Owens, S.M.; Betley, J.; Fraser, L.; Bauer, M.; et al. Ultra-high-throughput microbial community analysis on the Illumina HiSeq and MiSeq platforms. ISME J. 2012, 6, 1621-1624. [CrossRef]

40. Beerntsen, B.T.; James, A.A.; Christensen, B.M. Genetics of Mosquito Vector Competence. Microbiol. Mol. Biol. Rev. 2000, 64, 115-137. [CrossRef]

41. Beard, C.; O'Neill, S.; Tesh, R.; Richards, F.; Aksoy, S. Modification of arthropod vector competence via symbiotic bacteria. Parasitol. Today 1993, 9, 179-183. [CrossRef]

42. Chouin-Carneiro, T.; Vega-Rua, A.; Vazeille, M.; Yebakima, A.; Girod, R.; Goindin, D.; Dupont-Rouzeyrol, M.; Lourenço-DeOliveira, R.; Failloux, A.-B. Differential Susceptibilities of Aedes aegypti and Aedes albopictus from the Americas to Zika Virus. PLoS Neglected Trop. Dis. 2016, 10, e0004543. [CrossRef] [PubMed]

43. Roundy, C.M.; Azar, S.R.; Rossi, S.L.; Huang, J.H.; Leal, G.; Yun, R.; Fernandez-Salas, I.; Vitek, C.J.; Paploski, I.A.; Kitron, U.; et al. Mosquito Competence for Zika Virus Transmission. Emerg. Infect. Dis. 2017, 23, 625-632. [CrossRef] [PubMed]

44. Souza-Neto, J.A.; Powell, J.R.; Bonizzoni, M. Aedes aegypti vector competence studies: A review. Infect. Genet. Evol. 2019, 67, 191-209. [CrossRef] [PubMed]

45. Tsetsarkin, K.; VanLandingham, D.L.; E McGee, C.; Higgs, S. A Single Mutation in Chikungunya Virus Affects Vector Specificity and Epidemic Potential. PLoS Pathog. 2007, 3, e201. [CrossRef]

46. Tsetsarkin, K.; McGee, C.; Higgs, S. Chikungunya virus adaptation to Aedes albopictus mosquitoes does not correlate with acquisition of cholesterol dependence or decreased $\mathrm{pH}$ threshold for fusion reaction. Virol. J. 2011, 8, 376. [CrossRef]

47. Wiggins, K.; Eastmond, B.; Alto, B.W. Transmission potential of Mayaro virus in Florida Aedes aegypti and Aedes albopictus mosquitoes. Med. Vet. Entomol. 2018, 5, 1-7.

48. Muñoz, M.; Navarro, J.C. Virus Mayaro: Un arbovirus reemergente en Venezuela y Latinoamérica. Biomédica 2012, 32, 288-302. [CrossRef]

49. Moore, C.G.; Mitchell, C.J. Aedes albopictus in the United States: Ten-Year Presence and Public Health Implications. Emerg. Infect. Dis. 1997, 3, 329-334. [CrossRef]

50. Smith, G.C.; Francy, D.B. Laboratory studies of a Brazilian strain of Aedes albopictus as a potential vector of Mayaro and Oropouche viruses. J. Am. Mosq. Control. Assoc. 1991, 7, 89-93.

51. Pereira, T.N.; Carvalho, F.D.; De Mendonça, S.F.; Rocha, M.N.; Moreira, L.A. Vector competence of Aedes aegypti, Aedes albopictus, and Culex quinquefasciatus mosquitoes for Mayaro virus. PLoS Neglected Trop. Dis. 2020, 14, e0007518. [CrossRef]

52. Xia, H.; Wang, Y.; Atoni, E.; Zhang, B.; Yuan, Z. Mosquito-Associated Viruses in China. Virol. Sin. 2018, 33, 5-20. [CrossRef]

53. Fraser, J.E.; De Bruyne, J.T.; Iturbe-Ormaetxe, I.; Stepnell, J.; Burns, R.L.; Flores, H.A.; O'Neill, S.L. Novel Wolbachia-transinfected Aedes aegypti mosquitoes possess diverse fitness and vector competence phenotypes. PLoS Pathog. 2017, 13, e1006751. [CrossRef]

54. Van Tol, S.; Dimopoulos, G. Influences of the mosquito microbiota on vector competence. In Advances in Insect Physiology; Elsevier: Amsterdam, The Netherlands, 2016; Volume 51, pp. 243-291.

55. Rossi, P.; Ricci, I.; Cappelli, A.; Damiani, C.; Ulissi, U.; Mancini, M.V.; Valzano, M.; Capone, A.; Epis, S.; Crotti, E.; et al. Mutual exclusion of Asaia and Wolbachia in the reproductive organs of mosquito vectors. Parasites Vectors 2015, 8, 1-10. [CrossRef]

56. Mousson, L.; Zouache, K.; Arias-Goeta, C.; Raquin, V.; Mavingui, P.; Failloux, A.-B. The Native Wolbachia Symbionts Limit Transmission of Dengue Virus in Aedes albopictus. PLoS Neglected Trop. Dis. 2012, 6, e1989. [CrossRef]

57. Robinson, C.M.; Pfeiffer, J.K. Viruses and the Microbiota. Annu. Rev. Virol. 2014, 1, 55-69. [CrossRef]

58. Ramirez, J.L.; Souza-Neto, J.; Cosme, R.T.; Rovira, J.; Ortiz, A.; Pascale, J.M.; Dimopoulos, G. Reciprocal Tripartite Interactions between the Aedes aegypti Midgut Microbiota, Innate Immune System and Dengue Virus Influences Vector Competence. PLoS Neglected Trop. Dis. 2012, 6, e1561. [CrossRef]

59. Minard, G.; Mavingui, P.; Moro, C.V. Diversity and function of bacterial microbiota in the mosquito holobiont. Parasites Vectors 2013, 6, 146. [CrossRef] 
60. Yadav, K.K.; Bora, A.; Datta, S.; Chandel, K.; Gogoi, H.K.; Prasad, G.B.K.S.; Veer, V. Molecular characterization of midgut microbiota of Aedes albopictus and Aedes aegypti from Arunachal Pradesh, India. Parasites Vectors 2015, 8, 1-8. [CrossRef]

61. Hughes, G.L.; Rivero, A.; Rasgon, J.L. Wolbachia Can Enhance Plasmodium Infection in Mosquitoes: Implications for Malaria Control? PLoS Pathog. 2014, 10, e1004182. [CrossRef]

62. Dodson, B.L.; Hughes, G.L.; Paul, O.; Matacchiero, A.C.; Kramer, L.D.; Rasgon, J.L. Wolbachia Enhances West Nile Virus (WNV) Infection in the Mosquito Culex tarsalis. PLoS Neglected Trop. Dis. 2014, 8, e2965. [CrossRef]

63. Raquin, V.; Moro, C.V.; Saucereau, Y.; Tran, F.H.; Potier, P.; Mavingui, P. Native Wolbachia from Aedes albopictus blocks chikungunya virus infection in cellulo. PLoS ONE 2015, 10, 1-19. [CrossRef]

64. Pan, X.; Pike, A.; Joshi, D.; Bian, G.; McFadden, M.J.; Lu, P.; Liang, X.; Zhang, F.; Raikhel, A.S.; Xiaoling, P. The bacterium Wolbachia exploits host innate immunity to establish a symbiotic relationship with the dengue vector mosquito Aedes aegypti. ISME J. 2018, 12, 277-288. [CrossRef] [PubMed]

65. Nazni, W.A.; Hoffmann, A.A.; NoorAfizah, A.; Cheong, Y.L.; Mancini, M.V.; Golding, N.; Kamarul, G.M.R.; Arif, M.A.K.; Thohir, H.; NurSyamimi, H.; et al. Establishment of Wolbachia Strain wAlbB in Malaysian Populations of Aedes aegypti for Dengue Control. Curr. Biol. 2019, 29, 4241-4248.e5. [CrossRef] [PubMed]

66. Ant, T.H.; Sinkins, S.P. A Wolbachia triple-strain infection generates self-incompatibility in Aedes albopictus and transmission instability in Aedes aegypti. Parasites Vectors 2018, 11,1-7. [CrossRef]

67. Vollmer, J.; Schiefer, A.; Schneider, T.; Jülicher, K.; Johnston, K.L.; Taylor, M.J.; Sahl, H.-G.; Hoerauf, A.; Pfarr, K. Requirement of lipid II biosynthesis for cell division in cell wall-less Wolbachia, endobacteria of arthropods and filarial nematodes. Int. J. Med. Microbiol. 2013, 303, 140-149. [CrossRef]

68. Molloy, J.C.; Sommer, U.; Viant, M.R.; Sinkins, S.P. Wolbachia Modulates Lipid Metabolism in Aedes albopictus Mosquito Cells. Appl. Environ. Microbiol. 2016, 82, 3109-3120. [CrossRef]

69. Wu, M.; Sun, L.V.; Vamathevan, J.; Riegler, M.; DeBoy, R.; Brownlie, J.C.; McGraw, E.A.; Martin, W.; Esser, C.; Ahmadinejad, N.; et al. Phylogenomics of the Reproductive Parasite Wolbachia pipientis wMel: A Streamlined Genome Overrun by Mobile Genetic Elements. PLoS Biol. 2004, 2, e69. [CrossRef]

70. Foster, J.; Ganatra, M.; Kamal, I.H.; Ware, J.; Makarova, K.S.; Ivanova, N.; Bhattacharyya, A.; Kapatral, V.; Kumar, S.; Posfai, J.; et al. The Wolbachia Genome of Brugia malayi: Endosymbiont Evolution within a Human Pathogenic Nematode. PLoS Biol. 2005, 3, e121. [CrossRef] [PubMed]

71. Joubert, D.A.; Walker, T.; Carrington, L.B.; De Bruyne, J.T.; Kien, D.H.T.; Hoang, N.L.T.; Chau, N.V.V.; Iturbe-Ormaetxe, I.; Simmons, C.P.; O'Neill, S.L. Establishment of a Wolbachia Superinfection in Aedes aegypti Mosquitoes as a Potential Approach for Future Resistance Management. PLoS Pathog. 2016, 12, e1005434. [CrossRef] [PubMed]

72. Axford, J.K.; Callahan, A.G.; Hoffmann, A.A.; Yeap, H.L.; Ross, P.A. Fitness of wAlbB Wolbachia Infection in Aedes aegypti: Parameter Estimates in an Outcrossed Background and Potential for Population Invasion. Am. J. Trop. Med. Hyg. 2016, 94, 507-516. [CrossRef] [PubMed]

73. Flores, H.A.; de Bruyne, J.T.; O’Donnell, T.B.; Nhu, V.T.; Giang, N.T.; Trang, H.T.X.; Van, H.T.T.; Long, V.T.; Huy, H.L.A.; Le Duyen, H.T.; et al. Multiple Wolbachia strains provide comparative levels of protection against dengue virus infection in Aedes aegypti. PLoS Pathog. 2020, 16, 1-17. [CrossRef]

74. de Thoisy, B.; Gardon, J.; Salas, R.A.; Morvan, J.; Kazanji, M. Mayaro Virus in Wild Mammals, French Guiana. Emerg. Infect. Dis. 2003, 9, 4. [CrossRef] 